\title{
Exploring New Strategies for Ultrahigh Strength Steel via Tailoring the Precipitates
}

\author{
Jialong Tian and Zhouhua Jiang* \\ School of Metallurgy, Northeastern University, Shenyang, China
}

Ultrahigh-strength (UHS) steels have shown great potential in the field of high-end equipment manufacturing in demand of lightweight engineering and performance upgrade. A significant research effort has been directed toward the development of advanced UHS steels with excellent combination of strength and toughness. In the course of development, tailoring precipitates by means of composition design and process optimization is absolutely a critical module. In this mini review, typical UHS steels strengthened by carbides and intermetallics are systematically summarized and discussed. With the increase of strength, the toughness losses of UHS steels strengthened by carbides and intermetallics have been compared in detail. In

OPEN ACCESS

Edited by:

Zengbao Jiao,

Hong Kong Polytechnic University, Hong Kong SAR, China

Reviewed by:

Yuting $L v$,

Shandong University of Science and

Technology, China

Song Xiang,

Guizhou University, China

${ }^{*}$ Correspondence:

Zhouhua Jiang

jiangzh@smm.neu.edu.cn

Specialty section: This article was submitted to

Structural Materials, a section of the journal

Frontiers in Materials

Received: 19 October 2021 Accepted: 25 November 2021 Published: 23 December 2021

Citation:

Tian J and Jiang Z (2021) Exploring New Strategies for Ultrahigh Strength

Steel via Tailoring the Precipitates.

Front. Mater. 8:797798.

doi: $10.3389 /$ fmats.2021.797798 particular, the in-depth mechanisms leading to various strength/toughness variation trends have been discussed, extracting the bottleneck in developing new-generation UHS steels containing merely one type of precipitate. Meanwhile, prospects on designing advanced UHS steels strengthened by coexisting dispersive precipitates have been proposed to achieve better performance.

Keywords: ultrahigh strength steel, alloy design, strength, fracture toughness, precipitates

\section{INTRODUCTION}

Ultrahigh-strength (UHS) steels, which exhibit ultimate tensile strength above 1,300 $\mathrm{MPa}$, are widely used in the most challenging structural applications, such as aircraft landing gear, rocket cases, high-performance shafts and rings, and other critical sectors (Jeckins et al., 1993; Wanhill et al., 2017). In addition to strength, actually there exist other vital issues which are always the determining factor in the materials selection. The high strength must be combined with toughness to resist fracture, ductility for safety coefficient in service, and resistance to corrosion damage (Sun et al., 2014; Tian, J. et al., 2017; Wang, L. et al., 2005). Three basic classes of UHS steels won out in the multi-property selection process to become key competitors for UHS steel applications:

i) High-strength low-alloy (HSLA) steel: $300 \mathrm{M}$ (contains $0.4 \% \mathrm{C}$, generally used for firstgeneration aircraft landing gear) (Youngblood et al., 1977), M50 (contains $0.8 \% \mathrm{C}$, widely applied to second-generation aircraft bearing) (Rydel et al., 2017);

ii) Maraging steels: Custom 465 (famous high-strength stainless steel) (Daymond et al., 2016), $18 \mathrm{Ni}$ (strongest UHS with acceptable ductility and toughness) (Wang, B. et al., 2017), PH 13-8Mo (well-known high-strength stainless steel) (Leitner et al., 2011);

iii) Co-Ni secondary hardening steels: Aermet 100 (used for second-generation aircraft landing gear) (Wang, L. et al., 2005), Ferrium S53 (developed for manufacturing advanced aircraft landing gear serviced in a marine environment) (Kuehmann et al., 2008). 
TABLE 1 | Compositions and mechanical properties of the conventional ultrahigh-strength steels.

\begin{tabular}{|c|c|c|c|c|c|c|c|c|c|}
\hline wt\% & $300 \mathrm{M}$ & 4,340 & M50 & $\begin{array}{c}\text { Custom } \\
465\end{array}$ & $18 \mathrm{Ni}$ & $\begin{array}{c}\text { PH } \\
\text { 13-8Mo }\end{array}$ & Aermet100 & $\begin{array}{l}\text { Ferrium } \\
\text { S53 }\end{array}$ & $\begin{array}{l}\text { Ferrium } \\
\text { M54 }\end{array}$ \\
\hline C & 0.41 & 0.42 & 0.84 & 0.0046 & 0.003 & 0.03 & 0.23 & 0.21 & 0.30 \\
\hline $\mathrm{Cr}$ & 0.78 & 0.83 & 4.15 & 10.70 & $x$ & 12.70 & 3.10 & 10.00 & 1.00 \\
\hline $\mathrm{Ni}$ & 1.77 & 1.78 & $\times$ & 10.90 & 17.70 & 8.20 & 11.10 & 5.50 & 10.00 \\
\hline Co & $x$ & $\times$ & $\times$ & $\times$ & 14.70 & $\times$ & 13.40 & 14.00 & 7.00 \\
\hline Mo & 0.42 & 0.24 & 4.20 & 0.86 & 6.73 & 2.20 & 1.20 & 2.00 & 2.00 \\
\hline $\mathrm{Ti}$ & $x$ & $\times$ & $\times$ & 1.40 & 1.23 & $x$ & $\leq 0.05$ & $\times$ & $\leq 0.02$ \\
\hline $\mathrm{Al}$ & $\times$ & $\times$ & $\times$ & 0.04 & $\times$ & 1.10 & $\times$ & $\times$ & $\times$ \\
\hline $\mathrm{Cu}$ & $\times$ & 0.03 & $\times$ & $x$ & $\times$ & $x$ & $x$ & $\times$ & $\times$ \\
\hline $\mathrm{Mn}$ & 0.65 & 0.78 & 0.20 & $\times$ & $x$ & $x$ & $x$ & $x$ & $x$ \\
\hline $\mathrm{Si}$ & 1.65 & 0.26 & 0.19 & $x$ & $x$ & $\times$ & $\times$ & $x$ & $\times$ \\
\hline W & $x$ & $\times$ & $x$ & $\times$ & $x$ & $x$ & $x$ & 1.00 & 1.30 \\
\hline V & 0.10 & $\times$ & 0.97 & $\times$ & $x$ & $x$ & $x$ & 0.30 & 0.10 \\
\hline Precipitates & Cementite/ع & Cementite/ع & $\begin{array}{c}\text { Cementite/M2C/ } \\
\text { M4C3 }\end{array}$ & $\mathrm{Ni}_{3} \mathrm{Ti}$ & $\mathrm{Ni}_{3} \mathrm{Ti} / \mathrm{R}$ & $\mathrm{NiAl} / \mathrm{M}_{2} \mathrm{C}$ & $\mathrm{M}_{2} \mathrm{C} / \mathrm{MC}$ & $\mathrm{M}_{2} \mathrm{C} / \mathrm{MC}$ & $\mathrm{M}_{2} \mathrm{C} / \mathrm{MC}$ \\
\hline YS (MPa) & 1,785 & 1,920 & 2,200 & 1,688 & 2,650 & 1,413 & 1,697 & 1,551 & 1,731 \\
\hline UTS (MPa) & 2,080 & 2,040 & 2,480 & 1,778 & 2,760 & 1,482 & 1,980 & 1,986 & 2,021 \\
\hline $\begin{array}{l}K_{\mathrm{IC}} \\
\left(\mathrm{MPa} \cdot \mathrm{m}^{1 / 2}\right)\end{array}$ & 57.4 & 53.0 & 18.6 & 70.5 & 31.6 & 127 & 132 & 71 & 110 \\
\hline $\begin{array}{l}\text { Stainless } \\
\text { References }\end{array}$ & $\begin{array}{c}\text { No } \\
\text { (JeckinsForrest, 1993; } \\
\text { YoungbloodRaghavan, } \\
\text { 1977) }\end{array}$ & $\begin{array}{c}\text { No } \\
\text { (JeckinsForrest, } \\
\text { 1993; Clarke } \\
\text { et al., 2014) }\end{array}$ & $\begin{array}{c}\text { No } \\
\text { (Hopkin et al., } \\
\text { 2017; } \\
\text { JeckinsForrest, } \\
\text { 1993) }\end{array}$ & $\begin{array}{c}\text { Yes } \\
\text { (Daymond } \\
\text { et al., 2016; } \\
\text { Ifergane } \\
\text { et al., 2015) }\end{array}$ & $\begin{array}{c}\text { No } \\
\text { Wang, } \\
\text { W. et al. } \\
(2010)\end{array}$ & $\begin{array}{c}\text { Yes } \\
\text { (David E. } \\
\text { Wert, } \\
\text { 2006; } \\
\text { Schnitzer } \\
\text { et al., 2010) }\end{array}$ & $\begin{array}{c}\text { No } \\
\text { WanhillAshok, } \\
(2017)\end{array}$ & $\begin{array}{c}\text { Yes } \\
\text { Kuehmann } \\
\text { et al. (2008) }\end{array}$ & $\begin{array}{c}\text { No } \\
\text { (Mondiere } \\
\text { et al., 2018; } \\
\text { Wang, C. C. } \\
\text { et al., 2018) }\end{array}$ \\
\hline
\end{tabular}

In these three classes of UHS steels, various alloying elements have been combined optimally to obtain the desirable microstructure and properties. All of them are processed to obtain the martensitic matrix and are hardened by an internal distribution of dispersive precipitates. At present, it has been widely accepted that lath martensite with high dislocation storage is the ideal matrix microstructure considering strength and toughness synergy (Sandvik et al., 1983; Morris et al., 2013; Galindo-Nava et al., 2015). However, there is still no unanimous viewpoint on the optimal precipitate and three aforementioned UHS steels differ in the nature of precipitates. HSLA steels usually use cementite $\mathrm{Fe}_{3} \mathrm{C}$ and $\varepsilon$-carbides, while maraging steels are strengthened by intermetallics such as $\eta-\mathrm{Ni}_{3} \mathrm{Ti}$ and $\mathrm{NiAl}$. In comparison, $\mathrm{Co}-\mathrm{Ni}$ secondary hardening steels introduce $\mathrm{M}_{2} \mathrm{C}$ and $\mathrm{MC}$ carbides. The present review aims in retrospect at the development of UHS steels with superior strength/toughness combinations and accounting for the most recent developments in this area. Various methods have been proposed to improve the performance of UHS steels. Modifying the steel with trace rare earth has been demonstrated to be effective to enhance the toughness (Malakondaiah et al., 1997; Gong et al., 2021). Meanwhile, the lamellar microstructure containing martensite and austenite indicates superior strength/toughness synergy (Liu, L. et al., 2020; Zhang et al., 2021). These two methods could be widely introduced into a variety of alloys. However, unique process technologies are usually matched to obtain the ideal property and this leads to the difficulty and stability in the manufacture process. In this work, we focus on the fundamental role of precipitates in achieving desirable properties of UHS steels and evaluate our current understanding on the intrinsic interactions between composition designing-precipitate features-properties. Following the detailed discussion, we will prospect the pathways that could be further performed to make a breakthrough in the field of UHS steels with exceptional combinations of strength and toughness, particularly concerning corrosion resistance.

\section{Developing Ultrahigh-Strength Steels With Upgraded Strength-Toughness Balance}

The first criterion in ranking the UHS steels according to their performance is the ratio of fracture toughness to ultimate tensile strength. In order to achieve the promising combination of strength and toughness, various alloy systems and processing routes have been developed. The compositions and the mechanical properties of some conventional UHS steels have been picked out, shown in Table 1. The ratio of fracture toughness to ultimate tensile strength of various UHS steels has been reviewed and represented by a diagram in Figure 1A (Hopkin et al., 2017; JeckinsForrest, 1993; Lv et al., 2011; Mondiere et al., 2018; Morris Jr, 2017; Niu et al., 2019; Schnitzer et al., 2010).

HSLA steels indicate rock-bottom balance of strength and toughness among three aforementioned classes of UHS steels. Obviously, the fracture toughness of HSLA steels sharply dropped to be around $25 \mathrm{MPa} \mathrm{m}{ }^{1 / 2}$ when reaching $1,600 \mathrm{MPa}$, except for three cases with better performance, while the cost of HSLA steels was the lowest, which is often the determining factor in the ultimate materials selection. For instance, in the past 50 years, conventional $300 \mathrm{M}$ steel has been widely used for the landing gear of civil aircraft. In order to enhance the strength of HSLA 


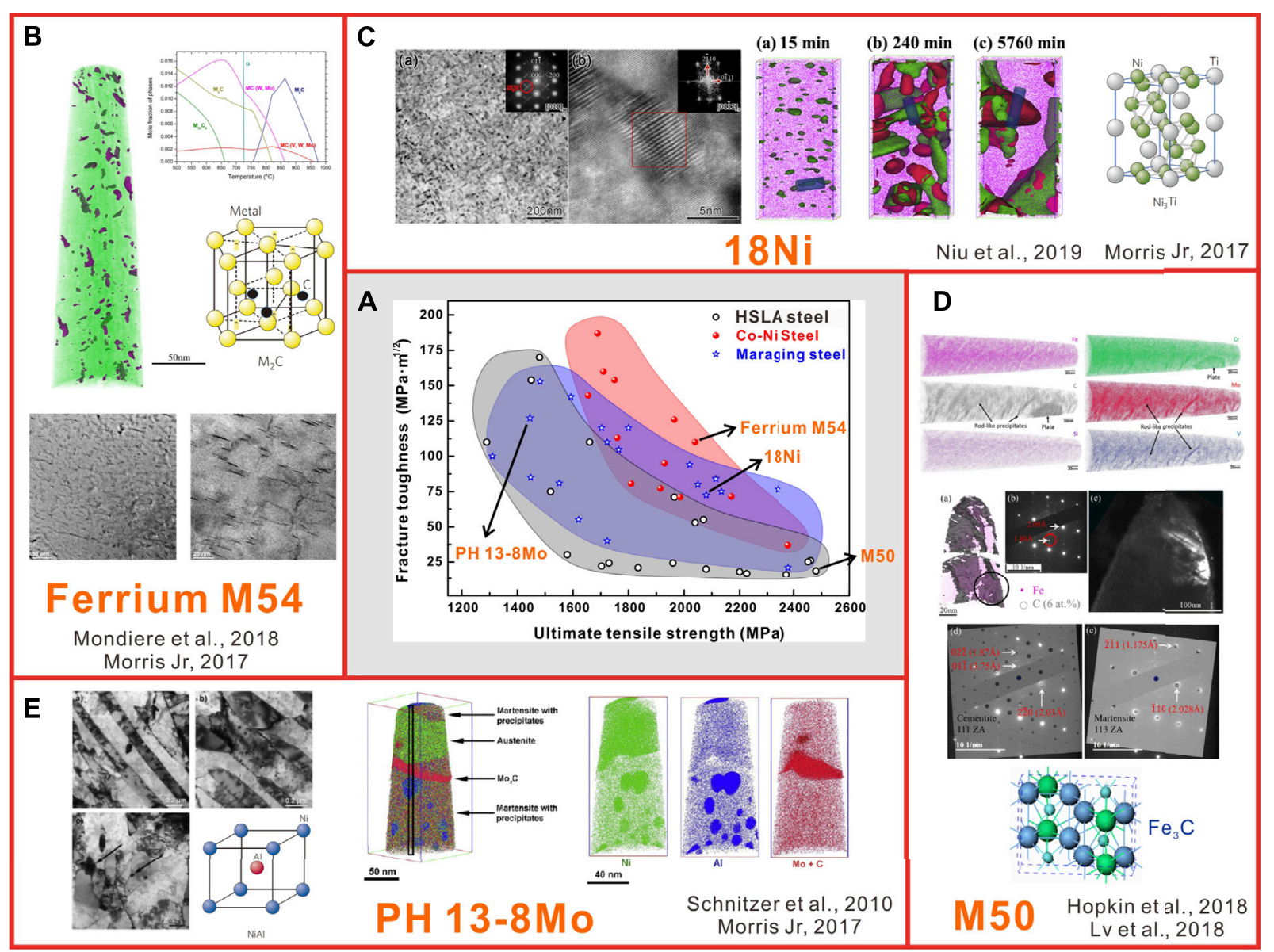

FIGURE 1 | (A) Fracture toughness - ultimate tensile strength diagram for several conventional UHS steels. (B-E) Microstructure characterizations showing the precipitates in Ferrium M54, 18Ni, M50 and PH 13-8Mo, respectively.

steels, the universal choice is to increase the carbon content. Unfortunately, higher carbon addition ( $>0.2 \mathrm{wt} \%$ ) would certainly result in the formation of twinned martensite in the quenching process (Pan et al., 2016; Stormvinter et al., 2011). In comparison to lath martensite, twinned martensite is a brittle matrix phase because of deficient plastic deformation and strain hardening capacity. In addition, coarse carbides are prone to form in the solidification and cooling process because of the high carbon content (Fukuda, 2006), thus seriously deteriorating the toughness (Leap, 2021). In conclusion, strengthening the UHS steels by increasing carbon content will deteriorate the toughness seriously, and this is not the ideal choice if neglecting the cost of the manufactured product.

In order to achieve better balance of properties to meet the property requirement of the aerospace field with no cost consideration, maraging steels came to the scene and gained intensive attention in the past decades (1950-1970) (Decker et al., 1988). In comparison to HSLA steels, superior strength/ toughness synergy of maraging steels should be attributed to the combination of carbon-free lath martensitic matrix and dispersive nano-size intermetallic precipitates. In conventional maraging steels, typical precipitates such as $\mathrm{Ni}_{3} \mathrm{Ti}, \mathrm{Ni}_{3} \mathrm{Mo}, \mathrm{NiAl}$, and $\varepsilon$-Cu have been usually introduced (Xu et al., 2010; Jiao et al., 2014; Jiao et al., 2015). Precipitation hardening is the dominant strengthening mechanism in maraging steels; thus, more precipitate-forming elements should be added in order to achieve a higher strength level. However, this will lead to a higher risk in forming harmful inclusions (such as $\mathrm{Al}_{2} \mathrm{O}_{3}$ and TiN) (Karr et al., 2017; Tian, J. et al., 2021); thus, special metallurgy technology will always be controlled meticulously to decrease the $\mathrm{O} / \mathrm{N}$ content to an extremely low level. In addition, attributed to lack in the interaction between interstitial $\mathrm{C}$ atoms and dislocation, the strain hardening factor of maraging steel is quite lower than that of C-strengthening steels. This acts as the obstacle to achieve better strength and toughness combination among classical maraging steels.

At present, the optimal combination of properties in UHS steels ought to be achieved in the Co-Ni secondary hardening steel, particularly at a higher strength level $(>1,800 \mathrm{MPa})$ indicated in Figure 1A. The design concept is to obtain lath martensite in the quenching process, achieved by setting the carbon content to be $0.2-0.3 \mathrm{wt} \%$. Furthermore, in order to reach a higher strength level at this carbon content level, dispersive 


\section{Pathway I : Co-precipitation of carbides and intermetallics}

A

Danoix et al., 2012

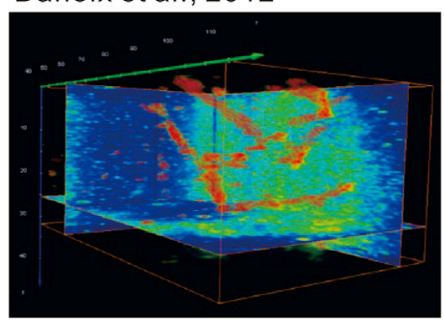

$\mathrm{NiAl}+$ Carbides
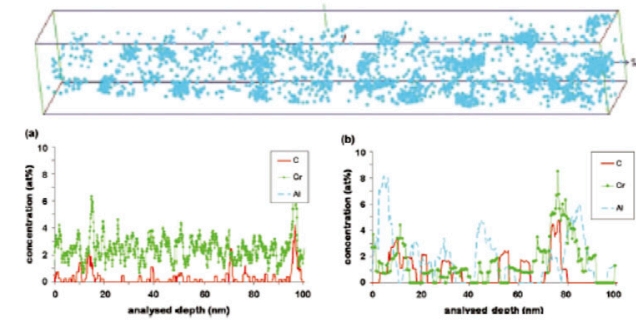

B Mulholland et al., 2011

$\varepsilon^{-} \mathrm{Cu}+$ Carbides
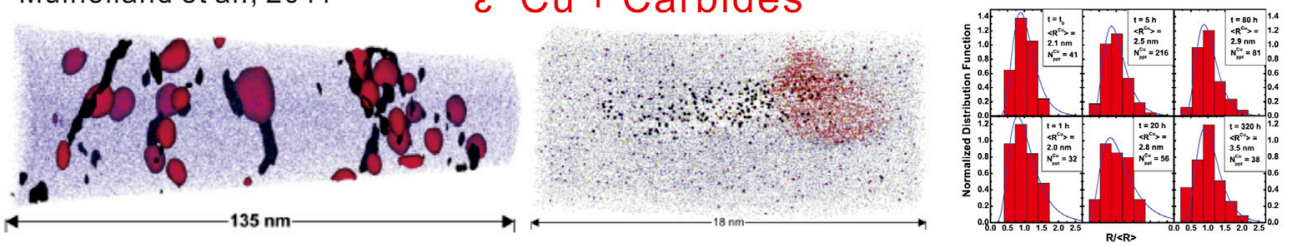

\section{Pathway II : Introduce nitrogen to form fine carbonitrides}

C Rietema et al., $2021 \quad \mathrm{~V}(\mathrm{C}, \mathrm{N})$
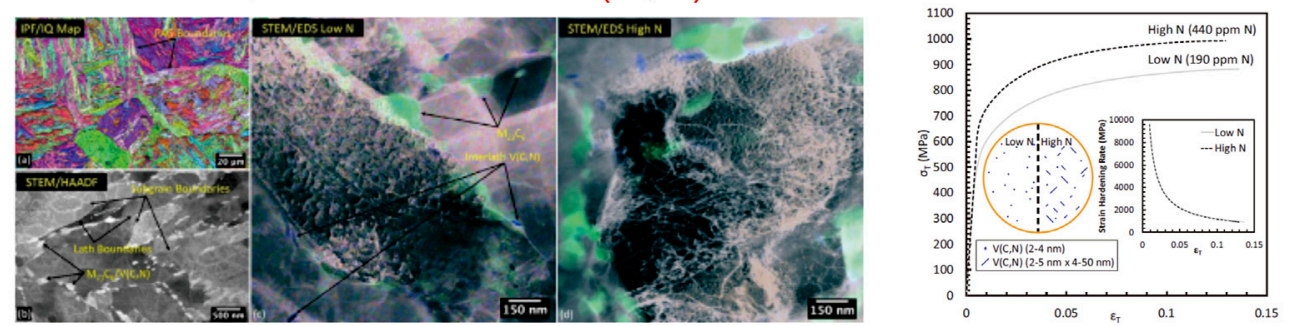

D

Feng et al., 2019

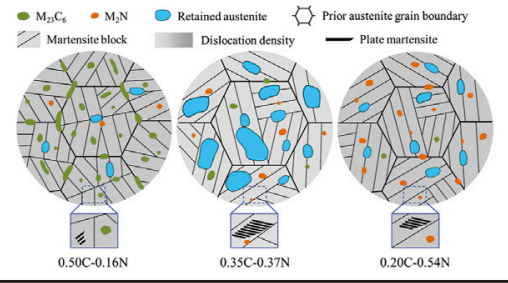

$\mathrm{M}_{23} \mathrm{C}_{6}+\mathrm{M}_{2} \mathrm{~N}$
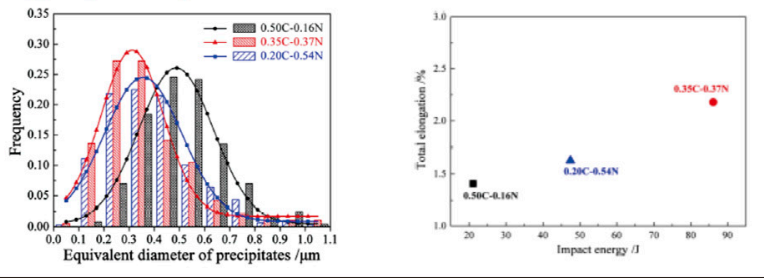

FIGURE 2 | Typical cases indicating the characters of precipitates in advance steels. (A) Co-precipitation of NiAl and carbides; (B) Co-precipitation of $\varepsilon$-Cu and carbides; (C) Introduce nitrogen to form $\mathrm{V}(\mathrm{C}, \mathrm{N})$ precipitates; (D) Substitution of carbon by nitrogen to form coexisting carbides and nitrides.

nano-size carbides $\left(\mathrm{M}_{2} \mathrm{C}, \mathrm{M}\right.$ usually denotes $\mathrm{Cr}$ or $\left.\mathrm{Mo}\right)$ are obtained via controlling the tempering process to trigger a strong secondary hardening effect (Mondiere et al., 2018; Wang, C. C. et al., 2018). Based on previous studies and the Orowan precipitate hardening mechanism, the secondary hardening phenomenon should be attributed to the magical effect of cobalt, which could lead to smaller precipitates accompanying a higher number density (Helis et al., 2009; Murthy et al., 2012). Absolutely, a high Ni content was another key point to guarantee the toughness. In summary, the pioneering nature of $\mathrm{Co}-\mathrm{Ni}$ secondary hardening in three classes of UHS steels could be attributed to the following aspects: toughening the matrix by obtaining a lath martensite, retaining suitable interstitial C atoms to guarantee a high strain hardening factor, modifying carbides by cobalt addition to trigger a strong secondary hardening effect, and weakening the risk to form harmful inclusions. 


\section{Prospects on Candidate Pathways to Make Breakthrough: Concentrating on Tailoring Precipitates}

Besides the strength-toughness balance, corrosion resistance of the UHS steel (itself, with no protected coating) is also a critical indicator that usually dominates the material selection property; particularly, the candidate materials will be subjected to extreme mechanical loads and harsh environmental conditions where corrosion is an important issue (Liu, Z. B. et al., 2014). Despite numerous studies in developing UHS stainless steels, many issues are still unsettled, leaving space for new ideas. In the year 2008, in order to solve the existing dilemmas between strength and corrosion resistance when selecting high specific-strength steels for critical landing gear components, QuesTek Innovations has designed Ferrium S53 to serve as a UHS corrosion-resistant drop-in replacement for $300 \mathrm{M}$ (Kuehmann et al., 2008). The fracture toughness in $3.5 \%$ salt water $\left(K_{\text {ISCC }}\right)$ was the main concern when evaluating the performance of similar UHS stainless steels. Thus, the current challenge is to achieve better balance of toughness and corrosion resistance at the objective strength level.

Ferrium S53 is actually the derivate of traditional secondary hardening steels, which has been modified by $10 \% \mathrm{Cr}$ addition to guarantee sufficient chromium in the matrix to provide passivation against corrosion. Approximately $14 \mathrm{wt} \%$ cobalt has been added to trigger a strong secondary hardening effect by forming nanoscale $\mathrm{M}_{2} \mathrm{C}$ carbides. Under the funding from Boeing Company, cooperating with Institute of Metal Research, we have performed systematic studies on developing an optimal UHS stainless steel used for manufacturing critical aircraft landing gear (Tian, J. et al., 2017). A fundamental breakthrough has been perceived: cobalt could accelerate the spinodal decomposition of $\mathrm{Cr}$ atoms during the tempering/ aging process, which would deteriorate the corrosion resistance of UHS stainless steels (Tian, J. et al., 2016; Tian, J. L. et al., 2018). This phenomenon was also the key factor leading to aforementioned dilemma between strength and corrosion resistance. Thus, the content of cobalt has to be decreased to eliminate the spinodal decomposition of $\mathrm{Cr}$ atoms. This composition-optimizing concept has been demonstrated to be feasible in previous research (Tian, J. et al., 2017), and the novel UHS stainless steel with low cobalt content (7 wt\%) indicated a better balance of strength and corrosion resistance. However, it still leaves space for performance improvement.

In order to offset the strength loss caused by lowering the cobalt content, new ideas are urgently needed to produce strong secondary hardening effects in the tempering/aging process. It has been mentioned that the nature of the cobalt-driven secondary hardening phenomenon was that cobalt addition could lead to smaller precipitates accompanying a higher number density. Thus, concentrating on the routes to enhance the precipitation hardening mechanism by tailoring the precipitates features, two candidate pathways based on literature summary and authors' intelligence have been prospected (Figure 2).
One candidate pathway is to produce a microstructure strengthened by co-precipitation of nanoscale carbides and intermetallic precipitates. The objective microstructure could evade the limitation of the microstructure with individual-type strengthening precipitate (maraging steel use intermetallic phase, secondary hardening steel employ carbide). Tracing back to 3 decades ago, researchers have succeeded in developing highstrength steels by incorporating multi-precipitates of nanometerscale $\mathrm{M}_{2} \mathrm{C}$ carbides and intermetallic NiAl phases (Danoix et al., 2011; Garrison et al., 1988; Hamano, 1993). It has been demonstrated that the $\mathrm{NiAl}$ particle itself could provide strong precipitation hardening contribution. In addition, it could lead to significant modification of the precipitation sequence and the arrangement of carbide nucleation sites compared to the steel with individual-type precipitate (Delagnes et al., 2012). At the initial stage of tempering, $\mathrm{NiAl}$ usually precipitates out of the supersaturated solid solution. In the following, a part of carbides would nucleate on the nano-size $\mathrm{NiAl}$ precipitates to form a core-shell structure. This interaction mechanism could provide considerable secondary hardening contribution even without high cobalt addition. The nanoscale $\mathrm{M}_{2} \mathrm{C}$ carbides are sufficiently small, and this frees chromium ions to be incorporated into the passive film in a corrosive environment. In a similar case (Mulholland et al., 2011; Jain et al., 2016), it has been demonstrated that multiple precipitates containing $\varepsilon-\mathrm{Cu}$ intermetallic phase and $\mathrm{M}_{2} \mathrm{C}$ carbide could contribute to the enhancement of both strength and toughness. Definitely, coprecipitation of nanometric carbides and intermetallics provides a candidate pathway to achieve better balance of strength, toughness, and corrosion resistance.

Another candidate pathway is to introduce nitrogen alloying to form ultrafine carbonitrides. The concept of alloying steels with carbon + nitrogen has been realized in martensitic stainless steel. The advantage of this idea has been sufficiently demonstrated in Cronidur-30 (Seifert et al., 2015), an advanced aircraft bearing steel with excellent mechanical and corrosive properties. Similar to carbon, nitrogen is also an interstitial element in steel and could provide strong interstitial solid solution strengthening contribution. Meanwhile, the nitrogen element has revealed some unique features and this leads to the possibility of improving the steel's performance by optimizing the carbon/ nitrogen combinations (Gavriljuk et al., 2008; Seifert et al., 2015). Naturally, nitrogen has benefit effects on corrosion resistance of steel because of its modification function on passive film ( $\mathrm{Ha}$ et al., 2009). In comparison to carbon steel or nitrogen steel, alloying martensitic steels with carbon + nitrogen contributes to an increased concentration of free electrons and an enhanced metallic character of interatomic bonds (Gavriljuk et al., 2008). This mechanism amounts to an increase in the ductility and toughness of the martensitic matrix, thus allowing to increase the strength level of UHS steel with trace loss of ductility and toughness. Another important aspect that needs to be concerned is the precipitate's characteristics (including composition, size, and density) that could be tailored dramatically via nitrogen alloying. A recent work has reported that introducing nitrogen into martensitic stainless steel could facilitate the ultrafine $\mathrm{V}(\mathrm{C}, \mathrm{N})$ precipitate, which is a very effective 
strengthening precipitate (Rietema et al., 2021). Due to the intrinsic difference between carbide and nitride, partial substitution of carbon by nitrogen turned out to be a promising concept to achieve better performance (Feng et al., 2019; Gavriljuk et al., 1999). As a result of nitrogen addition, the composition and structure of precipitates in carbon steel will be dramatically modified. Since nitrogen will destabilize a part of carbides $\left(\mathrm{Cr}_{23} \mathrm{C}_{6}\right.$ is a case), particular carbonitrides with high thermodynamic stability are prone to precipitate $[\mathrm{V}(\mathrm{C}, \mathrm{N})$ is a typical case]. In addition, unmixed carbide and unmixed nitride would precipitate separately depending on thermodynamics and kinetics factors. Thus, introducing nitrogen into martensitic steel could trigger fine precipitates, which are promising microstructure units to achieve excellent combination of strength, toughness, and corrosion resistance.

\section{DISCUSSION}

UHS steels with good balance of strength and toughness are key materials for lightweight engineering design strategies and corresponding $\mathrm{CO}_{2}$ savings. Over the past decades, there have been significant achievements in the development of novel UHS steels under the efforts of both academia and industry. In this mini review, the strength-toughness balance of three conventional classes of UHS steels is analyzed contrastively.

\section{REFERENCES}

Clarke, A. J., Miller, M. K., Field, R. D., Coughlin, D. R., Gibbs, P. J., Clarke, K. D., et al. (2014). Atomic and Nanoscale Chemical and Structural Changes in Quenched and Tempered 4340 Steel. Acta Materialia 77, 17-27. doi:10.1016/j.actamat.2014.05.032

Danoix, F., Danoix, R., Akre, J., Grellier, A., and Delagnes, D. (2011). Atom Probe Tomography Investigation of Assisted Precipitation of Secondary Hardening Carbides in a Medium Carbon Martensitic Steels. J. Microsc. 244 (3), 305-310. doi:10.1111/j.1365-2818.2011.03537.x

Daymond, B. T., Binot, N., Schmidt, M. L., Preston, S., Collins, R., and Shepherd, A. (2016). Development of Custom 465 Corrosion-Resisting Steel for Landing Gear Applications. J. Materi Eng. Perform. 25 (4), 1539-1553. doi:10.1007/s11665-015-1830-5

Decker, R. F., and Floreen, S. (1988). Maraging Steel: Recent Developments and Applications in Maraging Steel - the First 30 years, The Minerals. Huntington: Metal \& Materials Society.

Delagnes, D., Pettinari-Sturmel, F., Mathon, M. H., Danoix, R., Danoix, F., Bellot, C., et al. (2012). Cementite-free Martensitic Steels: A New Route to Develop High Strength/high Toughness Grades by Modifying the Conventional Precipitation Sequence during Tempering. Acta Materialia 60 (16), 5877-5888. doi:10.1016/j.actamat.2012.07.030

Feng, H., Li, H.-B., Jiao, W.-C., Jiang, Z.-H., Cai, M.-H., Zhu, H.-C., et al. (2019). Significance of Partial Substitution of Carbon by Nitrogen on Strengthening and Toughening Mechanisms of High Nitrogen Fe-15Cr-1Mo-C-N Martensitic Stainless Steels. Metall. Mat Trans. A. 50 (11), 4987-4999. doi:10.1007/s11661-019-05398-4

Fukuda, T. (2006). Effect of Titanium Carbides on the Ductility and Toughness of High Carbon 30 Mass\% Chromium Steels. Mater. Trans. 47 (5), 1402-1407. doi:10.2320/matertrans.47.1402

Galindo-Nava, E. I., and Rivera-Díaz-del-Castillo, P. E. J. (2015). A Model for the Microstructure Behaviour and Strength Evolution in Lath Martensite. Acta Materialia 98, 81-93. doi:10.1016/j.actamat.2015.07.018

Garrison, W. M., and Strychor, R. (1988). A Preliminary Study of the Influence of Separate and Combined Aluminum and Nickel Additions on the Properties of a Secondary Hardening Steel. Mta 19 (12), 3103-3107. doi:10.1007/BF02647739
We discussed the fundamental mechanisms leading to a mechanical difference emphasizing on the precipitate, which is a key microstructure unit determining the performance of UHS steels. Coarse carbides and harmful inclusions should be the dominant inducements restricting a better strength/toughness synergy in HSLA steel and maraging steel, respectively. High Co-Ni secondary hardening steel has indicated an outstanding combination of strength and toughness, while there still leaves space for new ideas to upgrade, particularly concerning the corrosion resistance. In order to make a breakthrough, two candidate pathways focusing on tailoring the precipitates have been proposed, while more systematic future studies need to be performed to drive the exploitation and application of UHS stainless steels.

\section{AUTHOR CONTRIBUTIONS}

All authors listed have made a substantial, direct, and intellectual contribution to the work and approved it for publication.

\section{FUNDING}

This work is supported by the National Natural Science Foundation of China (Grant numbers 52004059 and U1908223).

Gavriljuk, V. G., and Berns, H. (1999). Precipitates in Tempered Stainless Martensitic Steels Alloyed with Nitrogen, Carbon or Both. Msf 318-320, 71-80. doi:10.4028/MSF.318-320.7110.4028/www.scientific.net/msf.318320.71

Gavriljuk, V. G., Shanina, B. D., and Berns, H. (2008). A Physical Concept for Alloying Steels with Carbon+nitrogen. Mater. Sci. Eng. A 481-482 (1), 707-712. doi:10.1016/j.msea.2006.11.186

Gong, W., Wang, C., Wang, P.-f., Jiang, Z.-h., Wang, R., and Li, H.-b. (2021). Effect of La on Inclusions and Fracture Toughness of Low-alloy Ultra-high-strength 40CrNi2Si2MoVA Steel. J. Iron Steel Res. Int. 28 (11), 1408-1416. doi:10.1007/ s42243-021-00579-1

Ha, H., Jang, H., Kwon, H., and Kim, S. (2009). Effects of Nitrogen on the Passivity of Fe-20Cr alloy. Corrosion Sci. 51 (1), 48-53. doi:10.1016/j.corsci.2008.10.017

Hamano, R. (1993). The Effect of the Precipitation of Coherent and Incoherent Precipitates on the Ductility and Toughness of High-Strength Steel. Mta 24, 127-139. doi:10.1007/BF02669610

Helis, L., Toda, Y., Hara, T., Miyazaki, H., and Abe, F. (2009). Effect of Cobalt on the Microstructure of Tempered Martensitic 9Cr Steel for Ultra-supercritical Power Plants. Mater. Sci. Eng. A 510-511, 88-94. doi:10.1016/j.msea.2008.04.131

Hopkin, S. E., Danaie, M., Guetard, G., Rivera-Diaz-del-Castillo, P., Bagot, P. A. J., and Moody, M. P. (2017). Correlative Atomic Scale Characterisation of Secondary Carbides in M50 Bearing Steel. Philosophical Mag. 98 (9), 766-782. doi:10.1080/14786435.2017.1410290

Ifergane, S., Sabatani, E., Carmeli, B., Barkay, Z., Ezersky, V., Beeri, O., et al. (2015). Hydrogen Diffusivity Measurement and Microstructural Characterization of Custom 465 Stainless Steel. Electrochimica Acta 178, 494-503. doi:10.1016/ j.electacta.2015.08.016

Jain, D., Isheim, D., Hunter, A. H., and Seidman, D. N. (2016). Multicomponent High-Strength Low-alloy Steel Precipitation-Strengthened by Sub-nanometric Cu Precipitates and M2C Carbides. Metall. Mat Trans. A. 47 (8), 3860-3872. doi:10.1007/s11661-016-3569-5

Jeckins, L. R., and Forrest, R. D. (1993). Properties and Selection : Irons, Steels, and High-Performance Alloys. Met. Handbook 1.

Jelita Rydel, J., Toda-Caraballo, I., Guetard, G., and Rivera-Díaz-del-Castillo, P. E. J. (2018). Understanding the Factors Controlling Rolling Contact Fatigue 
Damage in VIM-VAR M50 Steel. Int. J. Fatigue 108, 68-78. doi:10.1016/ j.ijfatigue.2017.10.018

Jiao, Z. B., Luan, J. H., Miller, M. K., and Liu, C. T. (2015). Precipitation Mechanism and Mechanical Properties of an Ultra-high Strength Steel Hardened by Nanoscale NiAl and Cu Particles. Acta Materialia 97, 58-67. doi:10.1016/ j.actamat.2015.06.063

Jiao, Z. B., Luan, J. H., Zhang, Z. W., Miller, M. K., and Liu, C. T. (2014). Highstrength Steels Hardened Mainly by Nanoscale NiAl Precipitates. Scripta Materialia 87, 45-48. doi:10.1016/j.scriptamat.2014.05.006

Karr, U., Schuller, R., Fitzka, M., Schönbauer, B., Tran, D., Pennings, B., et al. (2017). Influence of Inclusion Type on the Very High Cycle Fatigue Properties of 18Ni Maraging Steel. J. Mater. Sci. 52 (10), 5954-5967. doi:10.1007/s10853017-0831-1

Kuehmann, C., Tufts, B., and Trester, P. (2008). Computational Design for Ultra High-Strength alloy. Adv. Mater. Process. 37, 40.

Leap, M. J. (2021). Effects of Secondary Void-Initiating Particles on the SteadyState Crack Growth Resistance of High-Strength Steel. Eng. Fracture Mech. 241, 107420. doi:10.1016/j.engfracmech.2020.107420

Leitner, H., Schnitzer, R., Schober, M., and Zinner, S. (2011). Precipitate Modification in PH13-8 Mo Type Maraging Steel. Acta Materialia 59 (12), 5012-5022. doi:10.1016/j.actamat.2011.04.053

Liu, L., Yu, Q., Wang, Z., Ell, J., Huang, M. X., and Ritchie, R. O. (2020). Making Ultrastrong Steel Tough by Grain-Boundary Delamination. Science 368 (6497), 1347-1352. doi:10.1126/science.aba9413

Liu, Z. B., Liang, J. X., Zhang, X. L., Yang, Z. Y., and Sun, G. Q. (2014). The Development and Application of High-Performance Ultra-high Strength Stainless Steel Subject to marine Environment. Msf 783-786, 867-874. doi:10.4028/MSF.783-786.86710.4028/www.scientific.net/msf.783-786.867

Lv, Z. Q., Fu, W. T., Sun, S. H., Bai, X. H., Gao, Y., Wang, Z. H., et al. (2011). Firstprinciples Study on the Electronic Structure, Magnetic Properties and Phase Stability of Alloyed Cementite with Cr or Mn. J. Magnetism Magn. Mater. 323 (7), 915-919. doi:10.1016/j.jmmm.2010.11.067

Malakondaiah, G., Srinivas, M., and Rao, P. R. (1997). Ultrahigh-strength Lowalloy Steels with Enhanced Fracture Toughness. Prog. Mater. Sci. 42 (1), 209-242. doi:10.1016/S0079-6425(97)00016-9

Mondiere, A., Déneux, V., Binot, N., and Delagnes, D. (2018). Controlling the MC and M2C Carbide Precipitation in Ferrium M54 Steel to Achieve Optimum Ultimate Tensile Strength/fracture Toughness Balance. Mater. Characterization 140, 103-112. doi:10.1016/j.matchar.2018.03.041

Morris Jr, J. W. (2017). Making Steel strong and Cheap. Nat. Mater 16 (8), 787-789. doi:10.1038/nmat 4949

Morris, J. W., Kinney, C., Pytlewski, K., and Adachi, Y. (2013). Microstructure and Cleavage in Lath Martensitic Steels. Sci. Technology Adv. Mater. 14 (1), 014208. doi:10.1088/1468-6996/14/1/014208

Mulholland, M. D., and Seidman, D. N. (2011). Nanoscale Co-precipitation and Mechanical Properties of a High-Strength Low-Carbon Steel. Acta Materialia 59 (5), 1881-1897. doi:10.1016/j.actamat.2010.11.054

Murthy, A. S., Medvedeva, J. E., Isheim, D., Lekakh, S. L., Richards, V. L., and Van Aken, D. C. (2012). Copper Precipitation in Cobalt-Alloyed PrecipitationHardened Stainless Steel. Scripta Materialia 66 (11), 943-946. doi:10.1016/ j.scriptamat.2012.02.039

Niu, M., Zhou, G., Wang, W., Shahzad, M. B., Shan, Y., and Yang, K. (2019). Precipitate Evolution and Strengthening Behavior during Aging Process in a 2.5 GPa Grade Maraging Steel. Acta Materialia 179, 296-307. doi:10.1016/ j.actamat.2019.08.042

Rietema, C. J., Hassan, M. M., Anderoglu, O., Eftink, B. P., Saleh, T. A., Maloy, S. A., et al. (2021). Ultrafine Intralath Precipitation of $\mathrm{V}(\mathrm{C}, \mathrm{N})$ in $12 \mathrm{Cr}-1 \mathrm{MoWV}$ (wt.\%) Ferritic/martensitic Steel. Scripta Mater. 197, 113787. doi:10.1016/ j.scriptamat.2021.113787

Sandvik, B. P. J., and Wayman, C. M. (1983). Characteristics of Lath Martensite: Part III. Some Theoretical Considerations. Mta 14 (4), 835-844. doi:10.1007/ BF02644286

Schnitzer, R., Radis, R., Nöhrer, M., Schober, M., Hochfellner, R., Zinner, S., et al. (2010). Reverted Austenite in PH 13-8 Mo Maraging Steels. Mater. Chem. Phys. 122 (1), 138-145. doi:10.1016/j.matchemphys.2010.02.058

Seifert, M., Siebert, S., Huth, S., Theisen, W., and Berns, H. (2015). New Developments in Martensitic Stainless Steels Containing C + N. Steel Research Int. 86 (12), 1508-1516. doi:10.1002/srin.201400503
Stormvinter, A., Borgenstam, A., and Hedström, P. (2011). Investigation of Lath and Plate Martensite in a Carbon Steel. Ssp 172-174 (3), 61-66. doi:10.4028/ www.scientific.net/SSP.172-174.61

Sun, M., Xiao, K., Dong, C. F., Li, X. G., and Zhong, P. (2014). Stress Corrosion Cracking of Ultrahigh Strength Martensite Steel Cr9Ni5MoCo14 in 3.5\% NaCl Solution. Aerosp. Sci. Technol. 36, 125-131. doi:10.1016/j.ast.2014.03.004

Tian, J.-L., Wang, W., Shahzad, M. B., Yan, W., Shan, Y.-Y., Jiang, Z.-H., et al. (2018). Corrosion Resistance of Co-containing Maraging Stainless Steel. Acta Metall. Sin. (Engl. Lett. 31 (8), 785-797. doi:10.1007/s40195-018-0758-9

Tian, J., Wang, W., Babar Shahzad, M., Yan, W., Shan, Y., Jiang, Z., et al. (2017). A New Maraging Stainless Steel with Excellent Strength-Toughness-Corrosion Synergy. Materials 10, 1293. doi:10.3390/ma10111293

Tian, J., Wang, W., Li, H., Yang, K., and Jiang, Z. (2021). Understanding Main Factors Controlling High Cycle Fatigue Crack Initiation and Propagation of High Strength Maraging Stainless Steels with Ti Addition. Mater. Sci. Eng. A 805, 140589. doi:10.1016/j.msea.2020.140589

Tian, J., Wang, W., Yin, L., Yan, W., Shan, Y., and Yang, K. (2016). Three Dimensional Atom Probe and First-Principles Studies on Spinodal Decomposition of $\mathrm{Cr}$ in a Co-alloyed Maraging Stainless Steel. Scripta Materialia 121, 37-41. doi:10.1016/j.scriptamat.2016.04.033

Wang, B., Zhang, P., Duan, Q. Q., Zhang, Z. J., Yang, H. J., Li, X. W., et al. (2017). Optimizing the Fatigue Strength of $18 \mathrm{Ni}$ Maraging Steel through Ageing Treatment. Mater. Sci. Eng. A 707, 674-688. doi:10.1016/ j.msea.2017.09.107

Wang, C.-c., Zhang, C., Yang, Z.-g., and Su, J. (2018). Carbide Precipitation and Element Distribution in High Co-ni Secondary Hardening Steel. J. Iron Steel Res. Int. 25 (3), 340-346. doi:10.1007/s42243-018-0041-3

Wang, L. D., Jiang, L. Z., Zhu, M., Liu, X., and Zhou, W. M. (2005). Improvement of Toughness of Ultrahigh Strength Steel Aermet 100. J. Mater. Sci. Technol. 21 (5), 710-714.

Wang, W., Yan, W., Duan, Q., Shan, Y., Zhang, Z., and Yang, K. (2010). Study on Fatigue Property of a New 2.8GPa Grade Maraging Steel. Mater. Sci. Eng. A 527 (13-14), 3057-3063. doi:10.1016/j.msea.2010.02.002

Wanhill, R., and Ashok, B. (2017). Aerospace Materials and Material Technologies. Kolkata, India: Indian Institute of Metals.

Wert, D. E., and Disabella, R. P. (2006). Strong Corrosion Resistant Stainless Steel Custom 465. Adv. Mater. Process. 164 (8), 34-36.

Xu, W., Rivera-Díaz-del-Castillo, P. E. J., Wang, W., Yang, K., Bliznuk, V., Kestens, L. A. I., et al. (2010). Genetic Design and Characterization of Novel Ultra-highstrength Stainless Steels Strengthened by Ni3Ti Intermetallic Nanoprecipitates. Acta Materialia 58 (10), 3582-3593. doi:10.1016/j.actamat.2010.02.028

Youngblood, J. L., and Raghavan, M. (1977). Correlation of Microstructure with Mechanical Properties of 300M Steel. Mta 8 (9), 1439-1448. doi:10.1007/ BF02642857

Zhang, H., Sun, M., Liu, Y., Ma, D., Xu, B., Huang, M., et al. (2021). Ultrafinegrained Dual-phase Maraging Steel with High Strength and Excellent Cryogenic Toughness. Acta Materialia 211, 116878. doi:10.1016/ j.actamat.2021.116878

Zhang, P., Chen, Y., Xiao, W., Ping, D., and Zhao, X. (2016). Twin Structure of the Lath Martensite in Low Carbon Steel. Prog. Nat. Sci. Mater. Int. 26 (2), 169-172. doi:10.1016/j.pnsc.2016.03.004

Conflict of Interest: The authors declare that the research was conducted in the absence of any commercial or financial relationships that could be construed as a potential conflict of interest.

Publisher's Note: All claims expressed in this article are solely those of the authors and do not necessarily represent those of their affiliated organizations, or those of the publisher, the editors, and the reviewers. Any product that may be evaluated in this article, or claim that may be made by its manufacturer, is not guaranteed or endorsed by the publisher.

Copyright $(0) 2021$ Tian and Jiang. This is an open-access article distributed under the terms of the Creative Commons Attribution License (CC BY). The use, distribution or reproduction in other forums is permitted, provided the original author(s) and the copyright owner(s) are credited and that the original publication in this journal is cited, in accordance with accepted academic practice. No use, distribution or reproduction is permitted which does not comply with these terms. 